\title{
Chemical Composition of Pistacia lentiscus Seeds' Oil from Moroccan High Atlas Mountain
}

\author{
Brahim Ait Mohand (D, ${ }^{1,2}$ Abderraouf El Antari, ${ }^{1}$ and Fatiha Benkhalti ${ }^{2}$ \\ ${ }^{1}$ Laboratory of Food Technology and Quality, National Institute of Agronomic Research, B. P. 533, Marrakech, Morocco \\ ${ }^{2}$ Laboratory of Bio-organic and Macromolecular Chemistry Department of Biology, Faculty of Sciences and Techniques, B. P. 549, \\ Marrakech, Morocco \\ Correspondence should be addressed to Brahim Ait Mohand; brahim.aitmohand@gmail.com
}

Received 21 January 2020; Accepted 25 April 2020; Published 13 May 2020

Academic Editor: Quancai Sun

Copyright (c) 2020 Brahim Ait Mohand et al. This is an open access article distributed under the Creative Commons Attribution License, which permits unrestricted use, distribution, and reproduction in any medium, provided the original work is properly cited.

\begin{abstract}
Pistacia lentiscus is an aromatic member of the Anacardiaceae family, endemic to the Mediterranean regions, which produces red and black oleaginous seeds in maturity. Our study focuses on the characterization of Pistacia lentiscus seed oils from three localities of High Atlas Mountain in the Azilal region of Morocco. Our results showed a very appreciable oil yield reaching more than $21 \%$ which clearly differs between the three sites studied $(21.33 \pm 0.17 \%$ in Boizoghrane, $15.22 \pm 0.10 \%$ in Tighanimine, and $7.67 \pm 0.29 \%$ in Tawjanizm locality); the analysis of the total fatty acids composition revealed a predominance of the unsaturated fatty acids represented essentially by the oleic and linoleic fatty acids, and also the triglyceride composition was dominated mainly by $\mathrm{POO}+\mathrm{SOL}, \mathrm{POL}+\mathrm{SLL}+\mathrm{PoOP}$, and OOO. This potential of the chemical composition offers the possibility of producing nutraceutical oil, which represents a source of income capable of insisting vulnerable local populations to protect this species from deforestation, thus maintaining biodiversity, and to reduce by this interest the migratory flow from marginal areas.
\end{abstract}

\section{Introduction}

Pistacia lentiscus, known as Mastic tree, is named in Morocco as "Drou" or "Tidit." This plant is a membership of the Anacardiaceae family. It is a three-meter-high branched shrub with a resin odor [1]. Its leaves are paripennial and persistent and are found in lowland, low, and medium mountains in Morocco, under semiarid, humid, subhumid, and perhumid bioclimates [2]. Moreover, lentisk is known for its medicinal properties since antiquity. In fact, it used and practiced in traditional medicines for treatment of ulcers, eczema, hypertension, sore throat, cough, and kidney stones [3]. Mastic seed oil is often used as an application remedy to treat burns or back pain [4].

Benhammou et al. [5] reported that this oil has good nutritive quality because of its content in unsaturated fatty acids (70\%) and saturated fatty acids (26\%). The triglyceride (TAG) composition of lentisk oil showed that the majority of TAGs of this oil are of mono- and polyunsaturated forms, and the main constituents are SOL + POO $(27.58 \pm 2.36 \%)$ followed by SLL + POL $(21.50 \pm 2.06 \%)$ [6]. According to Arab et al. [7], the yield of phenolic compounds obtained from Pistacia lentiscus fruit is $61.34 \%$ (vegetable powder), whereas the concentration of the phenolic fruit extract, expressed as gallic acid, is $31.81 \mathrm{mg} / \mathrm{ml}$.

The study of acute toxicity realized by Boukeloua et al. [8] showed a low toxicity of Pistacia lentiscus fixed oil. The high values of oral and intraperitoneal lethal doses of both $P$. lentiscus fixed oil administered in mice, respectively, ( $\mathrm{LD} 50=37 \mathrm{ml} / \mathrm{kg}$ body wt., $\mathrm{p}$. $\mathrm{o}$ and $\mathrm{LD} 50=2.52 \mathrm{ml} / \mathrm{kg}$ body wt., i. p.) show their low acute toxicity. The subchronic toxicity test conducted in rabbits at different doses $(0.5,1$, and $2 \mathrm{~mL} \mathrm{kg-1)}$ for 28 days via oral route also did not result in any signs of toxicity. The biochemical results indicate that this oil maintains the rates of aspartate amino transferase (AST) and alanine amino transferase (ALT) in the physiological norms [9]. 
However, until now, no studies have been made on the composition of the lentisk seeds, especially the chemical composition of the lipid profile, in the Azilal region, having a particular forest on the High Atlas Mountains with a favorable microclimate for several plants with high added values and also with a vulnerable population of which this plant can constitute a source of income in a spirit of protection of the biodiversity, and this region is characterized by a semiarid climate in the North and subhumid climate in the South. Therefore, the main objective of the presented work is to highlight the chemical composition of Moroccan lentisk seeds under the influence of pedoclimatic conditions of the study area.

\section{Materials and Methods}

2.1. Plant Material. Pistacia lentiscus seeds were harvested at full maturity (identical red color of seeds) from natural populations in three localities: Tawjanizm (TA), Boizoghrane (BO), and Tighanimine (TI) of the Azilal region (Morocco) (Table 1), during December 2015. Identification of the species was confirmed in regional herbarium MARK faculty of Sciences Semlalia in Marrakech (Morocco). A voucher specimen (MARK 10938) was deposited at the herbarium of this faculty. The seeds are taken manually from small and large plants of different heights (top and bottom) on the two sides of mountains and then mixed from each sampling site. Then, the seeds were sorted and thoroughly cleaned of all impurities, and after drying at $40^{\circ} \mathrm{C}$, the seeds were ground to obtain a powder.

2.2. Extraction and Oil Content. The extraction of the oil was carried out for 6 hours with hexane in a Soxhlet extraction system, and at the end of the extraction, the solvent is evaporated in a rotary evaporator under vacuum, with slight heating $\left(+30^{\circ} \mathrm{C}\right)$. The residual traces of hexane were removed by bubbling the extracted oil with nitrogen. The extracted oils are stored under nitrogen in the refrigerator until analysis.

2.3. Fatty Acid Composition. The total fatty acid composition of the lentisk oils was determined according to the AFNOR, T60-233, and T60-234 method. The methyl esters were then analyzed by gas chromatography (GC) using a Varian CP 3380 chromatograph with a flame ionization detector equipped with a capillary column packed with a stationary phase: CPWAX 52 CB (length: $25 \mathrm{~m}$, inner diameter: $0.25 \mathrm{~mm}$, and outer diameter: $0.39 \mathrm{~mm}$ ). The temperature of the oven is $180^{\circ} \mathrm{C}$, the temperature of the injector is $200^{\circ} \mathrm{C}$, and the temperature of the detector is $210^{\circ} \mathrm{C}$. The carrier gas is nitrogen.

2.4. Analysis of Triglycerides by HPLC. The method of triglyceride determination was according to the official method of the Commission of the European Union (1991). The analysis of triglycerides was carried out in a Jasco PU-2080 LC as well as an intelligent HPLC pump equipped with a
Jasco CO-2065 in addition to the furnace column and a Jasco RI-930 refractive index detector equipped with Jasco AS2055 autosampler. The column used was an omnisphere $5 \mu \mathrm{m} \mathrm{C18}$, length $250 \mathrm{~mm}$, and $4.6 \mathrm{~mm}$ ID. The conditions of the analysis were $50: 50 \mathrm{v} / \mathrm{v}$ acetone/acetonitrile solvent, $1.2 \mathrm{~mL} / \mathrm{min}$ flow rate, and $40^{\circ} \mathrm{C}$ oven temperature.

2.5. Statistical Analysis. All experiments were conducted in triplicate with SPSS Inc. software (version 13.0). One-way analysis of variance (ANOVA) was used to determine significant differences among means, with the significance level taken at $a=0.05$. Tukey's HSD test was used to perform multiple comparisons among means.

A principal component analysis was studied using factor analysis of XLSTAT statistical software version 2011. The relationships between harvest sites and the parameters studied were also evaluated by Pearson's product moment correlation at $P \leq 0.05$.

\section{Results and Discussion}

3.1. Oil Content. The seeds show a good oil yield, and the average values obtained from studied localities are shown in Figure 1. The highest oil content corresponded to Boizoghrane seed at $21.33 \pm 0.17 \%$. This value is almost consistent with that found by Boukeloua et al.'s study [8] of lentisk seeds from west of Skikda (Algeria) $(20.25 \% \pm 0.10)$, followed by Tighanimine at $15.22 \pm 0.10 \%$. This yield is higher than that reported by Charef et al. [10] (11.72\%) for red mastic fruit of lentisk collected from a forest located $70 \mathrm{~km}$ from the Algerian capital, and the lowest value was obtained for Tawjanizm seed oil at $7.67 \pm 0.29 \%$, which is close to the value obtained for P. lentiscus harvested in France by Ferlay (9.8\%).

The oilseeds of the lentisk from Boizoghrane and Tighanimine can be classified as oil-rich such as sunflower oil, peanut oil, palm oil, and soybean; therefore, these seeds can be used as a source of vegetable oil. On the contrary, the lentisk seeds taken from Tawjanizm, in which the oil content does not exceed $12 \%$, are classified as seeds moderately poor in fat.

From these results, it can be said that the oil yield of lentisk seeds is influenced by the sampling zone, and the large difference in the oil yield between the three localities can be explained by the maturity of the lentisk seeds (in fact, the amount of oil increases during the seed maturation phase) as reported by Charef et al. [10] (11.70\% for red fruits and $32.8 \%$ for black fruits) and also can be explained by the different bioclimatic conditions close to each site [11].

3.2. Fatty Acid Composition. The fatty acid composition of Pistacia lentiscus seeds is shown in Table 2. The lentisk oils of the three localities had high amounts of monounsaturated fatty acids (MUFA) with values between $52.43 \%$ and $53.67 \%$ of total fatty acids (TFA). It was followed by polyunsaturated fatty acids (PUFA) between $22.27 \%$ and $25.32 \%$ and then saturated fatty acids (SFA) representing 22.25 to $24.07 \%$ of TFA. The major FA was oleic acid (C18:1) with the highest 
TABLE 1: Geographical parameters of the three localities of lentisk seeds.

\begin{tabular}{|c|c|c|c|c|c|c|}
\hline Localities & Latitude & Length & $\begin{array}{l}\text { Level of the } \\
\text { sea }(\mathrm{m})\end{array}$ & $\begin{array}{c}\text { Annual } \\
\text { rain }(\mathrm{mm})\end{array}$ & $\begin{array}{l}\text { Minimum } \\
\text { average temperatures }\left({ }^{\circ} \mathrm{C}\right)\end{array}$ & $\begin{array}{c}\text { Maximum } \\
\text { average temperatures }\left({ }^{\circ} \mathrm{C}\right)\end{array}$ \\
\hline TA & $31^{\circ} 54^{\prime} 58^{\prime} 74^{\prime \prime} \mathrm{N}$ & $6^{\circ} 35^{\prime} 12^{\prime} 77^{\prime \prime} \mathrm{O}$ & 1422.86 & & & \\
\hline $\mathrm{BO}$ & $31^{\circ} 54^{\prime} 44^{\prime} 47^{\prime \prime} \mathrm{N}$ & $6^{\circ} 35^{\prime} 40^{\prime} 08^{\prime \prime} \mathrm{O}$ & 1410.44 & 260.3 & 4 to $10^{\circ} \mathrm{C}$ & 20 to $40^{\circ} \mathrm{C}$ \\
\hline TI & $31^{\circ} 54^{\prime} 8^{\prime} 33^{\prime \prime} \mathrm{N}$ & $6^{\circ} 35^{\prime} 47^{\prime} 78^{\prime \prime} \mathrm{O}$ & 1416.06 & & & \\
\hline
\end{tabular}

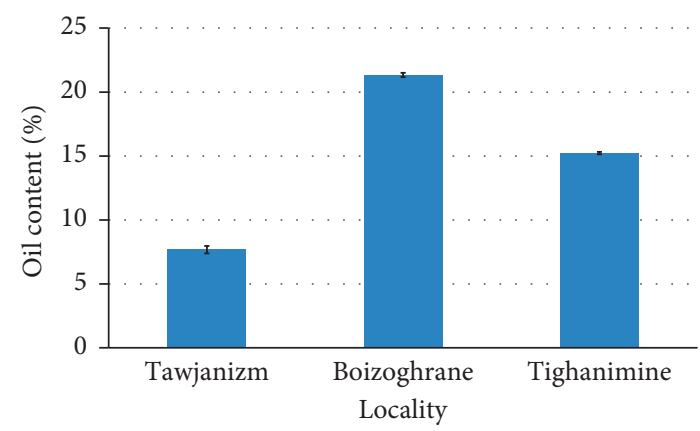

FIGURE 1: Oil content of lentisk seeds from the three localities.

amount of Boizoghrane seed oil (53.23\%), followed by Tawjanizm at $52.50 \%$. The lowest value corresponded to Tighanimine seed oil at $51.56 \%$. These values were similar to those reported by Dhifi et al. [6] and Charef et al. [10]. The oleic FA is reputed for its role in the preservation of cardiovascular diseases and its nutritional value [12]. Furthermore, linoleic acid (C18:2), an essential FA, accounted for $20.95 \%$ to $23.77 \%$ of whole $\mathrm{FA}$; it has favorable nutritional implications and beneficial physiological effects in the prevention of coronary heart disease and cancer [13], and it provides lipids necessary for cell membrane repair and cellular respiration [14]. For palmitic acid (C16:0), the highest value was detected in Boizoghrane seed oil at 23.01\% followed by Tawjanizm oil (22.55\%) and $20.51 \%$ for Tighanimine oil. The content of oleic acid, linoleic acid, and palmitic acid from three localities studied is consistent with the results obtained by Dhifi et al. [6].

The values obtained in unsaturated fatty acids (UFA) for the three localities are higher than those obtained by Dhifi et al. [6] and lower than those reported by Charef et al. [10]. This is explained by the absence of linolenic acid in the oils studied by Charef et al. [10]. The percentage of saturated fatty acids (SFA) is higher than that reported by Charef [10] and lower than those obtained by Dhifi et al. [6]. The low saturated/unsaturated FA ratio (0.35) reveals a high content in UFA which may give it nutritiona and, dietetic virtues and curative properties. The FA composition of Pistacia lentiscusseeds' oil is similar to that of Pistacia vera [15] and Pistacia atlantica [16]. The existence of omega 6 and 9 in this oil makes it as an alternative source of these essential FA. Furthermore, the profile of FA confirms the similarity between Pistacia lentiscus oils and other edible vegetable oils such as rapeseed, olive, sunflower, and cotton. The fatty acid profile of three oil samples is in accordance with the standards of the Codex Alimentarius for rapeseed oil concerning specially stearic acid, oleic acid, linoleic acid, and linolenic acid, and it also corresponds to that of olive oil in terms of the composition of palmitoleic acid (C16:1) and stearic acid (C18:0). On the contrary, the composition of the lentisk oils studied exceeds that of olive oil containing palmitic acid, linoleic acid, and linolenic acid. Thus, higher values of palmitic and palmitoleic acid compared with rapeseed oil are recorded. These findings are in agreement with the results reported by Dhifi et al. [6], but the percentage values were different. This inconsistency could be attributed to different causes, such as genotype and growing conditions.

3.3. Analysis of Triglycerides. The triglyceride composition of seeds' oil in the three localities revealed the existence of 16 triglycerides and had high amounts of $\mathrm{POO}+\mathrm{SOL}$, OOO, and POL + SLL + PoOP. The triglyceride (TAG) composition of lentisk showed that the majority of the TAGs is in monoand polyunsaturated forms (Table 3 ). Considering the fatty acid composition, the main constituents were stearoyloleyllinoleylglycerol (SOL) and palmitoyl-dioleylglycerol (POO) for 21.24 to $24.71 \%$ of the total TAGs. Stearoyl-dilinoleoylglycerol (SLL) and palmitoyl-oleyllinoleol glycerine (POL) accounted for 16.37 to $16.47 \%$ of the total TAGs, while trioleylglycerol (OOO) and dioleyl-linoleylglicerin (OOL) were significantly represented with quantities, respectively, of 15.28 to $16.02 \%$, and 11.57 to $14.44 \%$. These results are in agreement with those reported in the literature for a study on grape seed oils [6].

It should be noted that our oils are rich in triglycerides formed by the combination of oleic, linoleic, and palmitic fatty acids, which confirmed the composition results of fatty acids.

3.4. Statistical Analysis. The Pearson correlation coefficients between the oil content $(\mathrm{TH})$ and fatty acids values $(\mathrm{C} 16: 1$, $\mathrm{C} 17: 1, \mathrm{C} 18: 0, \mathrm{C} 18: 1$, and $\mathrm{C} 18: 2$ ) and triglycerides (OLL, SOS, SOO, OOO, POP, POL, POL + SLL + POOP, and $\mathrm{OOL}+\mathrm{PLnP}+\mathrm{PoOP}$ ) were calculated. Then, the analysis was performed to determine the strength of the relationship between the three sampling localities and the analytical parameters.

The correlation circle (Figure 2) represents the evolution and the relationship between the variables studied. Three distinguished groups of components were found. The first group corresponded to the correlation between oil content (TH), cis-10-heptadecanoic acid (C17:1), and oleyl-dilinoleoyl-glycerol (OLL). The second group showed a strong correlation between the two harvest sites Boizoghrane (BO) and Tawjanizm (TA) in terms of the composition in triglyceride (SOO). The third group consisted of triglycerides palmitoyl-dilinoleoyl-glycerol (PLL) and triglyceride (SOS) 
TABle 2: Pistacia lentiscus seed oil fatty acids composition (\%).

\begin{tabular}{|c|c|c|c|c|c|c|c|c|}
\hline & \multirow[b]{2}{*}{ TA } & \multirow[b]{2}{*}{$\mathrm{BO}$} & \multirow[b]{2}{*}{$\mathrm{TI}$} & \multirow{2}{*}{$\begin{array}{c}\text { Dhifi et al., } \\
2013 \\
\text { (Tunisia) }\end{array}$} & \multicolumn{2}{|c|}{ Charef et al., 2011 (Algeria) } & \multirow{2}{*}{$\begin{array}{l}\text { Olive oilCOI, } \\
2013\end{array}$} & \multirow[b]{2}{*}{$\begin{array}{l}\text { Rapeseed oil CODEX } \\
\text { STAN 210-1999 }\end{array}$} \\
\hline & & & & & $\begin{array}{c}\text { Pistacia.L } \\
\text { (black seeds) }\end{array}$ & $\begin{array}{l}\text { Pistacia.L (red } \\
\text { seeds) }\end{array}$ & & \\
\hline C16:0 & $22.55 \pm 0.02$ & $23.01 \pm 0.04$ & $20.51 \pm 0.11$ & $23.52 \pm 3.01$ & 19.5 & 16.3 & $7.50-20.00$ & $1.5-6.0$ \\
\hline $\mathrm{C} 16: 1$ & $0.38 \pm 0.16$ & $0.44 \pm 0.13$ & $0.53 \pm 0.23$ & $1.19 \pm 0.12$ & 2.1 & 1.0 & $0.30-3.50$ & ND-3.0 \\
\hline $\mathrm{C} 18: 0$ & $0.98 \pm 0.20$ & $1.05 \pm 0.10$ & $1.3 \pm 0.05$ & $1.41 \pm 0.02$ & 1.7 & 0.7 & $0.50-5.00$ & $0.5-3.1$ \\
\hline $\mathrm{C} 18: 1$ & $52.5 \pm 0.35$ & $53.23 \pm 0.53$ & $51.56 \pm 0.21$ & $51.06 \pm 4.37$ & 55.3 & 53.5 & $55.0-83.00$ & $8.0-60.0$ \\
\hline $\mathrm{C} 18: 2$ & $22.14 \pm 0.44$ & $20.95 \pm 0.45$ & $23.77 \pm 0.38$ & $20.71 \pm 2.25$ & 21.4 & 28.5 & $3.50-21.00$ & $11.0-23.0$ \\
\hline $\mathrm{C} 18: 3$ & $1.45 \pm 0.06$ & $1.31 \pm 0.02$ & $1.54 \pm 0.01$ & $0.47 \pm 0.10$ & - & - & $<1.00$ & $5.0-13.0$ \\
\hline MUFA & $52.88 \pm 0.06$ & $53.67 \pm 0.02$ & $52.43 \pm 0.12$ & $52.4 \pm 7.18$ & 57.4 & 54.5 & & \\
\hline PUFA & $23.59 \pm 0.51$ & $22.27 \pm 0.47$ & $25.32 \pm 0.38$ & $21.18 \pm 2.23$ & 21.4 & 28.5 & & \\
\hline SFA & $23.53 \pm 0.65$ & $24.07 \pm 0.56$ & $22.25 \pm 0.48$ & 26.42 & 21.2 & 17.0 & & \\
\hline $\begin{array}{l}\text { MUFA/ } \\
\text { PUFA }\end{array}$ & $2.24 \pm 0.05$ & $2.41 \pm 0.05$ & $2.07 \pm 0.04$ & 2.47 & 2.68 & 1.91 & & \\
\hline SFA/UFA & $0.31 \pm 0.01$ & $0.32 \pm 0.01$ & $0.29 \pm 0.01$ & 0.35 & 0.27 & 0.2 & & \\
\hline
\end{tabular}

MUFA monounsaturated fatty acids, MUFA polyunsaturated fatty acids, SFA saturated fatty acids, and UFA unsaturated fatty acids.

TABle 3: Triglyceride composition of the seed oil of Pistacia lentiscus by HPLC (\%).

\begin{tabular}{|c|c|c|c|c|}
\hline & TA & $\mathrm{BO}$ & $\mathrm{TI}$ & Dhifi et al. (2013) \\
\hline LLL & 2.64 & 2.26 & 3.40 & $1.32 \pm 0.28$ \\
\hline PLLn & 0.79 & 0.71 & 0.83 & \\
\hline OLL & 0.50 & 6.21 & 8.77 & $5.67 \pm 1.62$ \\
\hline PLL & 7.28 & 6.94 & 7.27 & $7.97 \pm 1.86$ \\
\hline POLn & 0.29 & 0.28 & 0.23 & \\
\hline $\mathrm{OOL}+\mathrm{PLnP}+\mathrm{PoOO}$ & 11.57 & 11.57 & 14.44 & $9.83 \pm 2.03$ \\
\hline $\mathrm{POL}+\mathrm{SLL}+\mathrm{PoOP}$ & 16.37 & 16.39 & 16.47 & $21.50 \pm 2.06$ \\
\hline PPL & 3.96 & 3.96 & 3.55 & $5.58 \pm 1.12$ \\
\hline $\mathrm{OOO}$ & 15.74 & 16.02 & 15.28 & $12.04 \pm 1.43$ \\
\hline $\mathrm{POO}+\mathrm{SOL}$ & 24.14 & 24.71 & 21.24 & $27.58 \pm 2.36$ \\
\hline POP & 7.91 & 8.31 & 6.42 & $8.51 \pm 1.09$ \\
\hline $\mathrm{GaOO}$ & 0.40 & 0.30 & 0.03 & \\
\hline SOO & 1.39 & 1.36 & 1.05 & \\
\hline POS & 0.94 & 0.97 & 0.99 & \\
\hline $\mathrm{AOO}$ & 0.05 & 0.03 & 0.03 & \\
\hline SOS & 0.04 & 0.00 & 0.02 & \\
\hline
\end{tabular}

LLL: trilinoleoyl-glycerol, OLLn: oleyl-linoleoyllinolenoylglycerol, OLL: oleyl-dilinoleoyl-glycerol, PLL: palmitoyl-dilinoleoyl-glycerol, OOL: dioleyllinoleoylglcerol, SLL: stearoyl-dilinoleoylglycerol, POL: palmitoyl-oleyl linoleoylglycerol, PPL: dipalmitoyllinoleoylglycerol, OOO: trioleylglycerol, SOL: stearoyloleyl-linoleoylglycerol, P OO: palmitoyl-dioleylglycerol, and PPO: dipalmitoyl-oleylglycerol.

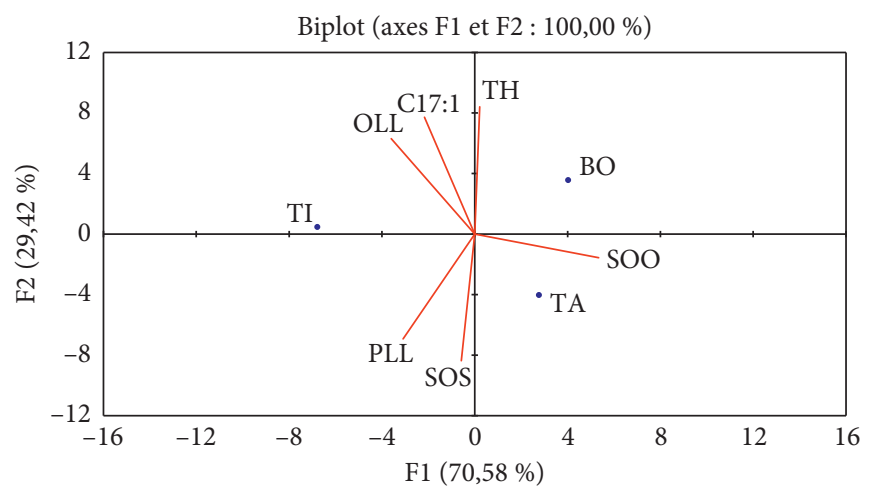

TA: Tawjanizm

BO: Boizoghrane

TI: Tighanimine

Figure 2: Correlation circle of variables according to PCA of the seed oil of Pistacia lentiscus and according to oil content fatty acid and triglyceride composition. 
that were highly correlated. The dispersion of the variables in this way showed a significant variability of the parameters studied under the effect of the sampling site.

The positive correlation is highly significant between the oil content and the C17:1 fatty acid, thus between the oil content and the OLL triglyceride on one side. On the contrary, the negative correlation is highly significant between the oil content and triglycerides (AOO, SOS and PLL). The strong correlation $(r>0.7)$ between cis-10-heptadecanoic acid and oleyl-dilinoleoyl-glycerol and their positive relationship with oil content and the negative relationship with triglycerides (AOO, SOS, and PLL) showed the importance of these five parameters in the characterization of three oils studied.

The correlation circle and the biplot showed that the oils from three sampling sites analyzed were characterized by a very interesting composition diversity defined by three types (oil content, fatty acid composition, and triglyceride composition) of the lentisk oils and discriminated by the oil content that is the variable.

\section{Conclusion}

On the basis of our study, it may be concluded that the results of this work showed that the seeds of lentisk can be used as an edible oil source. This oil had an interesting oil yield and presents a high content in the unsaturated fatty acids. It is rich in C18:1 whose dietary virtues are well established and also rich in $\mathrm{C} 18: 2$ which is an essential FA with beneficial physiological effects. Those compounds may be used to study the potential use of oils from these seeds in pharmaceuticals, foodstuffs, and cosmetic industry. In a further work, we will try to complete this research by valorizing unsaponifiable matters in the oils evaluating biological activities and to evaluate toxicity of lentisk oil. Such study could achieve industrial application of this plant oil.

\section{Data Availability}

The data used to support the findings of this study are available from the corresponding author upon request.

\section{Conflicts of Interest}

The authors declare that they have no conflicts of interest.

\section{Acknowledgments}

The authors wish to thank a technical staff of Food Technology and Quality Laboratory of National Institute of Agronomic Research of Marrakech for providing support during the development of this research.

\section{References}

[1] D. More and J. White, Encyclopédie des Arbres Plus de 1800 Espèces et Variétés du Monde, Flammarion, vol. 18, p. 797, Paris, France, 2005.
[2] M. Fennane, M. Ibn Tattou, A. Ouyahya, and J. E. Oualidi, Série Botanique, Travaux de l'Institut Scientifique, vol. 2, p. 250, Rabat, Morocco, 2007.

[3] C. Gardeli, P. Vassiliki, M. Athanasios, T. Kibouris, and M. Komaitis, "Essential oil composition of Pistacia lentiscus L. and Myrtus communis L.: evaluation of antioxidant capacity of methanolic extracts," Food Chemistry, vol. 107, no. 3, pp. 1120-1130, 2008.

[4] J. Bellakhdar, La Pharmacopée Marocaine Traditionnelle. Médecine Arabe Ancienne et Savoirs Populaires, p. 764, Ibis Press, Paris, France, 1997.

[5] N. B. Benhammou, L. Belyagoubi, A. E. Belaskri et al., "Fatty acid composition and antioxidant activity of Pistacia lentiscus L. fruit fatty oil from Algeria," Journal of Food Measurement and Characterization, vol. 12, p. 1408, 2018.

[6] W. Dhifi, N. Jelali, E. Chaabani et al., "Chemical composition of Lentisk (Pistacia lentiscus L.) seed oil," African Journal of Agricultural Research, vol. 8, pp. 1395-1400, 2013.

[7] K. Arab, O. Bouchenak, and K. Yahiaoui, "Phytochemical study and evaluation of the antimicrobial and antioxidant activity of essential oils and phenolic compounds of Pistacia lentiscus L," Journal of Fundamental and Applied Sciences, vol. 6, pp. 77-91, 2015.

[8] A. Boukeloua, A. Belkhiri, Z. Djerrou, L. Bahri, and N. Boulebda, "Acute toxicity of Opuntia ficus indica and Pistacia lentiscus seed oils," African Journal of Traditional, Complementary and Alternative Medicines, vol. 9, pp. 607$611,2012$.

[9] Z. Maameri, Z. Djerrou, S. Habibatni, F. Riachi, and H. Djaalab, "Physicochemical characteristics and sub chronic oral toxicity of Pistacia lentiscus L.vegetable oil in rabbits," OnLine Journal of Biological Sciences, vol. 16, pp. 43-48, 2016.

[10] M. Charef, M. Yousfi, M. Saidi, and P. Stocker, "Determination of the fatty acid composition of acorn (quercus), Pistacia lentiscus seeds growing in Algeria," Journal of the American Oil Chemists' Society, vol. 85, no. 10, pp. 921-924, 2008.

[11] A. M. Cherif, Effets cicatrisants de produits à base d'huile de lentisque (Pistacia lentiscus L.) sur les brûlures expérimentales chez le rat, Ph.D. thesis, University of Frères Mentouri Constantine, Constantine, Algeria, 2016.

[12] P. Corbett, "It is time for an oil change! Opportunities for high oleic vegetables oils," Information, Food Technology, vol. 14, pp. 480-481, 2003.

[13] B. D. Oomah, S. Ladet, D. V. Godfrey, J. Liang, and B. Girard, "Characteristics of raspberry (Rubus idaeus L.) seed oil," Food Chemistry, vol. 69, no. 2, pp. 187-193, 2000.

[14] M. Loden and A.-C. Andersson, "Effect of topically applied lipids on surfactant-irritated skin," British Journal of Dermatology, vol. 134, no. 2, pp. 215-220, 1996.

[15] T. Chahed, I. Hamrouni, W. Dhifi, K. Msaada, M. E. Kchouk, and B. Marzouk, "Lipid evaluation during the development of Pistachio seed from the region of Kairouan (middle of Tunisia)," Journal of Food Lipids, vol. 13, no. 4, pp. 375-389, 2006.

[16] B. R. Ghalem and H. Benhassaini, "Etude des phytostérols et des acides gras de Pistachia atlantica," Afrique Science: Revue Internationale des Sciences et Technologie, vol. 3, pp. 405-412, 2007. 